\title{
A UTILIZAÇÃO DE RECURSOS INTERATIVOS PARA A INFOINCLUSÃO DE ALUNOS SURDOS DA EDUCAÇÃO DE JOVENS E ADULTOS
}

\author{
THE USE OF INTERACTIVE FEATURES FOR STUDENTS INFOINCLUSION \\ DEAF EDUCATION OF YOUNG PEOPLE AND ADULTS
}

\section{LA UTILIZACIÓN DE RECURSOS INTERACTIVOS PARA LA INFORMACIÓN DE ALUMNOS SURDOS DE LA EDUCACIÓN DE JÓVENES Y ADULTOS}

\author{
Elenira Aparecida Paschuini \\ Mestra em Educação pela Universidade Federal do Paraná (UFPR). Graduada em Letras \\ Português e Letras Libras (UEM). Pós-graduada em Educação Especial, LIBRAS/Língua \\ Portuguesa, em Educação Profissional EJA. Interprete/Tradutora LIBRAS. POLILIBRAS. \\ E-mail: elenirapas@gmail.com \\ Nuria Pons Vilardell Camas \\ Doutora em Educação: Currículo (PUCSP), Professora e Pesquisadora (UFPR) de \\ Tecnologias e Educação, professora e orientadora no Programa de Pós-graduação Mestrado \\ Educação: Teoria e Prática do Ensino na Universidade Federal do Paraná (UFPR). \\ E-mail: nuriapons@gmail.com
}

\begin{abstract}
RESUMO
O presente trabalho procura analisar a aprendizagem dos alunos surdos na modalidade da educação de jovens e adultos (EJA), desenvolvendo uma sequência didática que analisa aspectos da cultura surda, dentro da perspectiva sócio interacionista para o envolvimento desse aluno na cibercultura. As dificuldades encontradas pelos surdos usuários de Libras no acesso à informação, à comunicação, à interatividade e interação são desafiadoras nesta pesquisa, bem como a intenção de rever metodologias utilizadas na EJA. Questiona-se, também, o papel do conhecimento da cultura surda como principal ponto de desenvolvimento de habilidades cognitivas e sociais da pessoa com surdez. Na perspectiva inclusiva, apontamos para a importância da tecnologia no avanço educacional. Portanto, propondo uma metodologia com recursos interativos, busca-se contribuir com o respeito à cultura surda e sua cidadania na atualidade.
\end{abstract}

Palavras-chave: Infoinclusão. Alunos Surdos. Educação de Jovens e Adultos. Cibercultura.

\section{ABSTRACT}

This paper aims to análise the learning of deaf students in the Youth and Adult Education (EJA), developing a teaching sequence that investigates aspects of deaf culture within the social interactionist perspective for tha student involvement in the cyberculture. The difficulties encountered by deaf users Brazilian Sign Language (Libras) in access to information, communication, interactivity and interaction are challenging this research, as well as the intention to review methodologies used in youth and adults education. The role of deaf culture knowledge is also questioned as the main point of development of cognitive and social skills of the person with deafness. The inclusive perspective, we point to the importance of technology 
in the educational advancement. Therefore, proposing a methodology with interactive features, it sought to contribute to respect for deaf culture and citizenship nowadays.

Keywords: Infoinclusion. Deaf Students. Youth and Adult Education. Cybercultura.

\section{RESUMEN}

El presente trabajo busca analizar el aprendizaje de los alumnos sordos en la modalidad de la educación de jóvenes y adultos (EJA), desarrollando una secuencia didáctica que analiza aspectos de la cultura sorda, dentro de la perspectiva socio interaccional para la participación de ese alumno en la cibercultura. Las dificultades encontradas por los sordos usuarios de las Libras en el acceso a la información, a la comunicación, a la interactividad e interacción son desafiantes en esta investigación, así como la intención de revisar metodologías utilizadas en la EJA. Se cuestiona, también, el papel del conocimiento de la cultura sorda como principal punto de desarrollo de habilidades cognitivas y sociales de la persona con sordera. En la perspectiva inclusiva, apuntamos a la importancia de la tecnología en el avance educativo. Por lo tanto, proponiendo una metodología con recursos interactivos, se busca contribuir con el respeto a la cultura sorda y su ciudadanía en la actualidad.

Palabras clave: Infoinclusión. Alumnos Sordos. Educación de Jóvenes y Adultos. Cibercultura

\section{INTRODUÇÃO}

O presente trabalho é um recorte da pesquisa maior realizada no Mestrado em Educação Teoria e Prática de Ensino, do Setor de Educação da Universidade Federal do Paraná (UFPR). Tentamos abordar, neste trabalho, a cultura digital a partir de um grupo que representa uma comunidade surda. Partimos da ideia de que, com o século XXI, as políticas mundiais de inclusão social, de acessibilidade à informação e à comunicação emergem nos diferentes espaços, valendo problematizar a utilização das tecnologias digitais no contexto daqueles que fazem uso da língua de sinais: Libras.

Intencionamos, com base na historicidade, questionar as abordagens clínicas terapêuticas que marcaram os problemas e fracassos escolares, principalmente nas fases da escola regular da maioria das pessoas surdas que procuram a Educação de Jovens e Adultos (EJA) e, buscamos também sugerir caminhos metodológicos para o desenvolvimento do ensino-aprendizagem utilizando formas mais tecnológicas.

Nesta proposição acreditamos que, atualmente, os estudos sobre surdez e sobre a educação da pessoa surda apontam para um grande leque de possibilidades de discussões. Portanto, o presente estudo pretende pesquisar a educação de surdos utilizando-se da tecnologia digital de informação e comunicação (TDIC).

Embora a questão inicial seja ampla, ela progressivamente se estreita e tornase mais focada durante o processo de pesquisa à medida que conceitos e suas relações são descobertos. Assim, a questão da pesquisa começa como uma 
questão aberta e ampla, mas não tão aberta, evidentemente, para permitir todo um universo de possibilidades (STRAUSS, 2008).

Nossa pesquisa parte do marco teórico estabelecido pela mediação do professor com seus estudantes, em nosso caso específico alunos surdos, (VYGOSTSKY, 1998), no sentido de além de dar o empoderamento do uso da Libras (SKLIAR, 1999, 2006; STROBEL, 2006; QUADROS, 1997; PERLIN, 1998), também de poderem se sentir, independente de sua condição, atores incluídos em seu tempo histórico por meios tecnológicos (SANTAELLA, 2007; LEVY,1999; COLL, 2010; MONOREO, 2010; CAMAS, 2008; CAMAS et al., 2013).

Esta pesquisa ocorreu no ambiente escolar da modalidade EJA, no estado do Paraná, em uma escola pública estadual. Vivenciamos as dificuldades encontradas pelos surdos usuários da Libras no acesso à informação, à comunicação, à interatividade e interação. Assim sendo, tentamos trazer para este artigo os caminhos que trilhamos na nossa vivência e análise de modo a podermos contribuir com o respeito à cultura surda e sua cidadania na atualidade.

Deste modo, nossa pesquisa parte da abordagem qualitativa (LÜDKE; ANDRÉ, 2013), em que os pesquisadores adotam a observação participante tanto no reconhecimento do problema quanto na comunidade envolvida, assim como na ação pedagógica construída. Utilizamos como instrumentos de coleta de dados uma sequência didática de dois momentos com duração aproximadamente de quarenta e cinco minutos, para a realização de atividades de exploração de recursos tecnológicos, compreensão de conteúdo estudado e produção textual. Em um terceiro momento, propomos a realização de um questionário pré-estabelecido.

Nossa preocupação advém de que a tecnologia digital ocupa um papel importante em vários aspectos da vida cotidiana moderna e para o aluno surdo também. Acrescentamos que, conforme Lévy (1999, p.159), o acesso às redes sociais, por meio da internet, mudou a maneira de como vemos e aprendemos sobre o mundo, mudando também nossa relação com o saber.

Sabemos que formas de acesso à informação tendem a intensificar e multiplicar rapidamente e, mesmo com a exclusão daqueles que não se apropriam das alterações tecnossociais, não se pode mais ignorar a cibercultura da atualidade. A minoria linguística que é usuária da língua de sinais, geralmente, priva-se da plena interação proposta pelo universo online.

Tendo em vista os muitos alunos surdos matriculados na modalidade de educação de jovens e adultos, a presente pesquisa inclui a reflexão sobre as tecnologias e as possíveis maneiras que estas podem minimizar as dificuldades escolares encontradas pelo indivíduo surdo. Nesta perspectiva, buscamos possibilidades de interação no uso de metodologias com recursos tecnológicos que atendam aos aspectos da cultura surda. 
Neste contexto, aquilo que é valorizado pelas pessoas é produto da cultura em que o indivíduo está inserido, a sua língua e os seus movimentos em busca de adquirir direitos sociais. Nosso questionamento resulta da tentativa de encontrarmos propostas metodológicas para análises de interação digital dos sujeitos surdos.

Para este fim, traçamos como objetivo o intuito de analisar a aprendizagem dos alunos surdos na modalidade da educação de jovens e adultos com a utilização dos recursos tecnológicos procurando investigar, inclusive, aspectos da cultura surda presentes no momento de aplicação.

Propomos, portanto, discutir as possibilidades de utilização de recursos tecnológicoeducacionais para surdos com relação ao desenvolvimento da aprendizagem frente ao atual processo inclusivo.

\section{A LIBRAS}

Libras - Língua Brasileira de Sinais é a língua oficial das pessoas surdas, como também oficial no Brasil e, deveria ser aprendida por todos nas escolas, assim como se aprende a Língua Portuguesa, a Língua Inglesa entre outras que possam fazer parte do Currículo Nacional. Para a inclusão dos surdos na Educação regular, partimos do que Skliar (2006) considerou como sendo uma abordagem sócio-antropológica. Essa concepção, debatida nos cursos da área de surdez, aceita a diferença linguística e cultural dos surdos, questionando a abordagem clínico-terapêutica, que marcou os problemas na educação desses alunos, que hoje frequentam as salas dos centros estaduais de educação básica para jovens e adultos.

A legislação e os movimentos surdos têm transformado este sujeito, que era considerado passivo no passado, em um indivíduo de direitos e de caracterização social diferenciada.

Os surdos formam uma comunidade linguística minoritária caraterizada por compartilhar uma Língua de Sinais e valores culturais, hábitos e modos de socialização próprios. A Língua de Sinais constitui o elemento identificatório dos surdos, e o fato de constituir-se em comunidade significa que compartilham e conhecem os usos e normas de uso da mesma língua já que interagem cotidianamente em um processo comunicativo eficaz e eficiente. Isto é, desenvolveram as competências linguística, comunicativa e cognitiva por meio do uso da Língua de Sinais - própria de cada comunidade de surdos (SKLIAR, 1999, p.141) 
Ao abordarmos a cultura surda e suas devidas especificidades, propomos a necessidade de considerar também os aspectos sociais e históricos que se constituíram, através dos tempos, às bases dessa cultura.

Conforme observou Paschuini (2015), a perspectiva inclusiva deve provocar discussões no sentido de entendermos que o grande desafio dos educadores é estabelecer uma proposta de ensino que reconheça e valorize práticas culturais dos alunos. Isto sem perder de vista o conhecimento historicamente produzido, que constitui patrimônio de todos. Neste sentido, Quadros (1997) já nos alertava que na década de 1990, devido aos estudos desenvolvidos na área, adentrava-se na terceira fase da inclusão dos surdos na educação, representada pela educação bilíngue:

[...] os profissionais da área da surdez estão tendo acesso a informações que são resultados de pesquisas e estudos sobre as línguas de sinais, possibilitando assim uma retomada dos conceitos estruturados de surdez e língua de sinais. Assim a educação de surdos no Brasil está entrando em uma terceira fase, que caracteriza um período de transição. Os estudos estão apontando na direção de uma proposta educacional bilíngue (QUADROS, 1997, p.26).

Ao considerarmos que a terceira fase educacional é o bilinguismo, podemos pensar que a inclusão dos surdos também se pode dar no uso e entendimento de diferentes tecnologias, incluindo hoje as digitais. Portanto, podemos estar caminhando para a quarta fase da inclusão dos surdos na educação: a infoinclusão.

A inclusão das pessoas com algum tipo de limitação é um tema que vem despertando na sociedade o interesse e o desafio de buscar soluções urgentes e práticas para atender essa população. Porém, vencer esses desafios, requer entendimento do conceito de "diferença" e, o que essa diferença provoca em nossos valores pré-estabelecidos sobre o que é anormalidade (PASCHUINI, 2015).

No caso dos surdos, há uma identificação com a deficiência e há dificuldade em admitir-se a existência de uma cultura surda. Essa cultura é multifacetada e apresenta características que lhe são específicas, ela é visual, ou seja, traduz-se de forma visual. As formas de organizar o pensamento e a linguagem transcendem as formas ouvintes (QUADROS, 1999, p. 27).

As questões linguísticas são essenciais, mas no caso dos alunos surdos adultos, essas questões vão além da linguagem, carregam diferenças culturais que precisam ser consideradas na modalidade de EJA. 
É importante ressaltarmos que, nas discussões da pesquisa sobre o processo inclusivo, refletimos e analisamos as metodologias utilizadas nas quais os recursos tecnológicos podem ser aplicados como ferramentas auxiliares no desenvolvimento das atividades escolares dos alunos surdos de EJA.

Segundo Boaventura Santos: "Temos o direito a ser iguais quando a nossa diferença nos inferioriza; e temos o direito a ser diferentes quando a nossa igualdade nos descaracteriza." (SANTOS, 2003, p.56).

Neste sentido, entendemos que se a língua de sinais é uma língua natural, adquirida de forma espontânea pela pessoa surda em contato com pessoas que usam essa língua e, se a língua oral é adquirida de forma sistematizada, destacamos que as pessoas surdas têm o direito de ser ensinadas na língua de sinais. E a proposta bilíngue busca captar esse direito (QUADROS, 1997, p.27).

\section{HISTÓRIA: UMA DIMENSÃO IMPORTANTE NA EDUCAÇÃO DO SURDO}

A dimensão histórica compreende o estudo e o entendimento de como o conceito principal dessa pesquisa evoluiu e se constituiu em um dos argumentos centrais da educação de surdos do século XIX. Essa apropriação da história e dos conceitos historicamente produzidos pretende estabelecer o conhecimento elaborado dos temas envolvidos - infoinclusão; surdez e educação tecnológica, revelando seus vínculos com conceitos contemporâneos.

Os estudos realizados por Strobel (2006) relatam que, desde a antiguidade, as pessoas surdas, assim como as pessoas com alguma deficiência, vivenciaram momentos de muito sofrimento, como extermínios e segregações. A partir da Idade Média até o século XIX, tentativas na educação de surdos apontavam para a adoção simultânea de duas vertentes: o início de técnicas gestuais, idealizada pelo abade L’Epée e, reabilitações sócio-educacionais com práticas oralistas.

Strobel (2006) afirma que os estudos oralistas consideravam os surdos brasileiros doentes ou deficientes. Os alunos surdos eram vistos como sujeitos que necessitavam de tratamento de cura. Por meio da classificação dos graus de surdez era possível pontuar o quanto os surdos se distanciavam da norma estabelecida socialmente.

A partir da década de 1990, propostas inovadoras começaram a surgir, objetivando a inclusão dos surdos no ensino regular. As instituições escolares deveriam considerar as especificidades dos surdos na elaboração de suas propostas pedagógicas. A oportunidade dada 
aos alunos surdos de frequentarem o ensino regular exigia uma adaptação ao sistema educacional de ensino, não considerando suas diferenças linguísticas e culturais.

No Brasil, as reais mudanças de paradigmas tiveram influência de dois eventos educacionais que discutiram o fracasso escolar. Primeiramente, a Conferência Mundial de Educação para Todos, em Jontien, Tailândia, no ano de 1990. Neste evento, discutiu-se maior atendimento de crianças na escola, incluindo os alunos com necessidades educacionais especiais.

O segundo evento importante para a prática docente inclusiva, foi a Conferência de Salamanca, em 1994, na Espanha. Propagou-se a questão da inclusão que, oferecendo oportunidades de aprendizagem a todos, cabia também à comunidade surda organizar movimentos que defendessem sua língua e cultura diferenciadas.

A legislação educacional no Brasil, por meio da Lei $n^{\circ} 10.098$ de 2000, prevê que o Poder Público deve tomar providências no sentido de eliminar as barreiras de comunicação, para garantir aos surdos o acesso à informação, à educação, incluindo a formação de intérpretes de língua de sinais.

O bilinguismo para a educação dos surdos, é uma proposta que objetiva resgatar e respeitar a língua de sinais. Muitos pesquisadores, como Quadros (2000) e Skliar (2006), defendem o reconhecimento desta abordagem que faz referência à utilização metodológica envolvendo o cotidiano dos surdos tanto na Língua Brasileira de Sinais e no Português contextualizado. A possibilidade do bilinguismo trouxe muitos avanços e conquistas na luta dos direitos das pessoas surdas, como a aprovação das Leis estaduais e federais que reconheceram a língua brasileira de sinais como primeira língua e língua portuguesa como a segunda língua.

Pensamos, portanto, que é importante manter uma estreita relação com os estudos históricos, no que se refere à educação de pessoas surdas, desde antiguidade até os dias de hoje, pois estes esclarecem fatores relevantes da situação da educação de surdos na atualidade.

\section{HOJE, QUAIS AS RELAÇÕES QUE PODEMOS ESTABELECER ENTRE O INTERNAUTA E O JOVEM SURDO?}

Em Paschuini (2015) sabemos que o perfil que identifica o jovem imerso no uso das tecnologias aponta para um sujeito também imerso na interatividade. No ciberespaço, todos se tornam iguais com relação às competências linguísticas. As sensações perceptivas e cognitivas que emergem nesse tipo de leitura estão ligadas ao mundo fascinante da informação virtual. No 
contexto da comunicação da pessoa surda o infonauta surdo pode olhar a informação e, por meio da percepção visual, aprender e entender a realidade social de uma nova maneira.

Nas relações estabelecidas pelo internauta do mundo ouvinte e um jovem surdo destacase um universo de mudanças onde todas as culturas devem ser valorizadas, entre elas a cultura surda (PASCHUINI, 2015). Acreditamos que há uma gama de problematizações referentes às dificuldades de comunicação do surdo e da sua inserção social. As dificuldades encontradas pelos surdos, usuários da Língua Brasileira de Sinais, no acesso à informação, à comunicação e à interatividade, são desafiadoras para esta pesquisa.

Já que a tecnologia ocupa um papel importante em vários aspectos da vida cotidiana moderna, faz-se necessário pesquisar, também, as relações do mundo pós-moderno com a preocupação do uso das tecnologias de informação e comunicação pelo aluno surdo.

As leis educacionais neste início de século contemplam o respeito pela LIBRAS Língua Brasileira de Sinais como língua oficial das pessoas surdas, concebe-se atualmente a educação de surdos sob uma concepção considerada por Skliar (2006), conforme já citado, como sendo uma abordagem sócio-antropológica. Essa concepção aceita a diferença linguística e cultural dos surdos, questionando a abordagem clínico-terapêutica que marcou os problemas na educação desses alunos, que hoje frequentam as salas dos centros estaduais de educação básica para jovens e adultos.

Reforçamos a idéia da diversificação da EJA com a Lei de Diretrizes e Bases da Educação Nacional (LDBEN n.9394/96), que no artigo 37, aponta que "a Educação de Jovens e Adultos será destinada àqueles que não tiveram acesso ou continuidade de estudos no Ensino Fundamental e Médio na idade própria". Nessa modalidade de ensino, percebe-se que os perfis dos educandos apresentam uma diversidade com relação à idade, à situação socioeconômica e, consequentemente, à caracterização da cultura.

Salientamos, nesta discussão, que a perspectiva da educação inclusiva tem trazido para o ambiente escolar muitas inquietações. Nesse sentido, o professor necessita de mais informação para poder entender como lidar com as diferenças e singularidades dos alunos que estão adentrando as salas de aula. Para que haja melhor preparo didático, há necessidade de mais conhecimento, quanto mais conhecimento, maior instrumentalização o professor terá na sua prática.

As implicações de ordem social, cultural e política que fazem parte da formação educacional do indivíduo, já se encontram presentes no perfil do jovem ou adulto surdo. Esse aluno traz consigo uma identidade fundamentada na especificidade de sua cultura surda. 
Salientamos, também, que existem muitas dificuldades encontradas pelos surdos usuários da Libras no acesso à informação de maneira geral. Neste sentido, há uma intenção de rever metodologias utilizadas na EJA questionando o papel do conhecimento da cultura surda como principal ponto de desenvolvimento de habilidades cognitivas e sociais da pessoa com surdez.

É fato que, apesar de muitos estudos recentes sobre esse assunto, ainda se fazem necessários avanços tecnológicos e metodológicos para a eficácia e aplicabilidade das leis de inclusão.

Os alunos jovens e adultos com alguma limitação precisam, por meio da mediação dos professores e de especialistas que se busque metodologias que visem o acesso à cultura da humanidade que é passada de geração para geração. A inclusão de surdos significa mais do que apenas criar vagas e proporcionar recursos materiais, é necessário que a escola e a sociedade sejam inclusivas, assegurando igualdade de oportunidades a todos os alunos, sempre contando com professores capacitados e compromissados com a educação de todos.

\section{METODOLOGIA}

Os aspectos metodológicos trazidos para esta pesquisa direcionam para uma metodologia dividida em dois eixos, que podem ser classificados como a dimensão histórica e a dimensão didática.

A dimensão didática envolve a aplicação e análise de material tecnológico, supostamente indicados aos alunos surdos do Ensino Médio da EJA. A pesquisa de abordagem qualitativa expressa neste estudo decorre do desejo de estabelecer um contraponto entre a metodologia que privilegia a Língua Portuguesa formal e o uso da Libras em material pedagógico tecnológico, pensando no hoje e no passado.

Os caminhos percorridos pela pesquisa e os passos de em uma sequência didática ${ }^{1}$ (ZABALA, 1998), da qual aplicamos atividades sobre o tema $e$-mail com fim de atender às análises da presente pesquisa. Considerando uma pesquisa de abordagem qualitativa no campo da ação, pretendemos, por meio dos instrumentos de coleta, abrir o debate sobre as amplas possibilidades da utilização das TIC para educação dos alunos surdos.

\footnotetext{
${ }^{1}$ Por sequência didática, partimos das teorias de Zabala (1998, p. 18) que entende sequências didáticas como "um conjunto de atividades ordenadas, estruturadas e articuladas para a realização de certos objetivos educacionais, que têm um princípio e um fim conhecido tanto pelos professores como pelos alunos".
} 
Ao propormos o uso de metodologias voltadas à cultura surda, intencionamos, questionar as abordagens clínico terapêuticas que marcaram os problemas e fracassos escolares nas fases da escola regular da maioria das pessoas surdas que procuram a EJA, bem como apontar caminhos de desenvolvimento da aprendizagem por formas mais tecnológicas.

A sequência pedagógica aplicada, na pesquisa de mestrado (PASCHUINI, 2015) procurou investigar alguns fatores trazidos da cultura surda, na perspectiva sócio-interacionista, para que os alunos participantes demonstrassem envolvimento na atual cibercultura para possibilidades de aquisição novos conhecimentos.

Trabalhamos a sequência didática com 05 (cinco) sujeitos surdos matriculados no Ensino Médio na modalidade EJA no CEEBJA, do município de Sarandi.

Realizamos dois momentos durante uma semana de aplicação, de duração aproximada de quarenta e cinco minutos, realizando atividades de exploração de aplicativos, de compreensão sobre o gênero textual e-mail e produção textual utilizando os recursos apresentados. Esta aplicação contou com 05 (cinco) tabletes cedidos para a pesquisa pelo Laboratório Interdisciplinar de Formação de Educadores, na Universidade Federal do Paraná, Setor de Educação.

Durante a análise dos resultados, discutimos também os aspectos sociológicos nos momentos de realização da pesquisa. Descrevendo nesta proposta uma pesquisa da sala de aula implementamos uma ação pedagógica capaz de levantar dados de análise.

A partir do trabalho de aplicação realizado (PASCHUINI, 2015), organizamos a categorização de análise, conforme a seguinte tabela:

Tabela 1: Categorização dos conteúdos da sequência didática
ALUNOS:
A.P. E.A.
E.T.
F.P
S.A. ${ }^{2}$

\begin{tabular}{|c|c|c|c|c|c|}
\hline Conteúdo Conceitual I & Não & Não & Não & Não & Não \\
\hline Conteúdo Conceitual II & Sim & Sim & Sim & Sim & Sim \\
\hline $\begin{array}{c}\text { Conteúdo } \\
\text { Procedimental }\end{array}$ & Não & Sim & Não & Sim & Não \\
\hline Conteúdo Atitudinal I & Não & Sim & Não & Não & Não \\
\hline Conteúdo Atitudinal II & Sim & Sim & Sim & Sim & Sim \\
\hline
\end{tabular}

\footnotetext{
${ }^{2}$ Por questão ética não identificamos os alunos participantes desta pesquisa, preferimos criar um código que não comprometesse nem a eles e nem a pesquisa, desta forma são identificados com as siglas: AP, EA; ET; FP, S.A. 
Segundo conceitos de Zabala (1998), por nós estudados (PASCHUINI, 2015) utilizamos a categorização por meio de conteúdos. Os conteúdos conceituais I e II, estão relacionados aos aspectos de definição e compreensão, respectivamente. No Conteúdo Conceitual I, percebemos que os cinco surdos confundiram seus depoimentos, pois ao serem indagados sobre o gênero estudado, todos relataram opiniões sobre a intenção da pesquisa e desviaram o assunto. No Conteúdo Conceitual II, os cinco participantes compreenderam as coordenadas das atividades e responderam corretamente às atividades propostas.

No Conteúdo Procedimental, consideramos a produção textual, observamos que os dois alunos surdos que têm maior vocabulário ou que já tem o conhecimento de sinais específicos tiveram mais facilidade, enquanto que os outros três não organizaram suas produções textuais seguindo a base proposta pelo pesquisador.

No Conteúdo Atitudinal I, considerado como a relação entre os sujeitos por meio de mensagem virtual, somente um aluno apresentou o resultado esperado: ele enviou sua mensagem via e-mail e seu destinatário recebeu esta mensagem sem a ocorrência de erros digitados. Os outros quatro alunos encontraram dificuldades tanto no preenchimento das janelas de mensagens, de login e senha, quanto na escrita e efetivação da mensagem.

Percebemos por meio das atividades propostas que a metodologia empregada na sequência didática atendeu aos objetivos deste estudo, porém faz-se necessário um apoio educacional mais direcionado às dificuldades de cada aluno em suas individualidades e especificidades pedagógicas. No entanto, reforçamos a proposição de mediação do professor nas intervenções pedagógicas (VYGOTSKY, 1998).

Com relação ao Conteúdo Atitudinal II, cujo parâmetro de análise dependia de respostas diretas ao questionário sobre as TIC, verificamos que todos aceitaram as ferramentas tecnológicas como auxiliares ao método educacional. Este fato respondido positivamente nos leva a constatar que a tecnologia é uma aliada nas práticas pedagógicas. Esta aceitação das TIC com apoio profissional proporciona um processo de cocriação, citado por Camas, Ribeiro e Mandaji (2013), pois, neste sentido, oferecemos aos sujeitos desta pesquisa um ambiente colaborativo e de construção de conhecimento. Acrescentando que favorecemos a interação para resolver as questões propostas de tradução e buscamos gerar ideias para criar juntos.

Nos momentos de aplicação para coleta de dados, a interpretação em Libras foi utilizada, referendando Vygotsky (1988) que defende a linguagem do indivíduo como meio de apropriação do mundo, pois esta proporciona a ele o desenvolvimento do seu pensamento. 
Nesta perspectiva e conforme os estudos de Fernandes (2003), reafirmamos as reflexões da autora com a preocupação de privilegiar o letramento da pessoa surda, uma vez que a falta deste letramento tem levado alguns alunos surdos ao fracasso escolar durante as últimas décadas.

Ao utilizarmos a Libras como base educacional na metodologia apresentada, lembramos que Skliar (1999) reforça que a modalidade da língua de sinais possui uma recepção visuogestual, sendo amplamente utilizada nos momentos de implementação das atividades realizadas. E, buscando, inclusive, compartilhar aspectos culturais e socializadores dos usuários da Libras, tivemos resultados potenciais nos registros em vídeo da opinião de cada participante.

Esclarecemos que a maioria do grupo, ou seja, os três alunos, não tinham conhecimento sobre e-mail e não sabiam para que servem as mensagens virtuais enviadas por este meio.

Ressaltamos que os fatores tecnológicos presentes no caminho metodológico apresentado, firma que não pensamos nas TIC como recursos para todas as soluções das dificuldades de aprendizagem, porém destacamos, conforme afirma Lemos (2013), que há um caminho equilibrado entre a negação do uso dos recursos tecnológicos e a euforia digital presente na época moderna.

Suas opiniões retratam que a língua do surdo e seus movimentos em busca de adquirir direitos sociais são os produtos da cultura e que estes devem ser respeitados. Se a língua de sinais é uma língua natural adquirida de forma espontânea pela pessoa surda em contato com pessoas que usam essa língua e se a língua oral é adquirida de forma sistematizada, então as pessoas surdas têm o direito de ser ensinadas na língua de sinais. (QUADROS, 1997, p.27)

Pelos depoimentos dados, aferimos que as questões linguísticas são essenciais, principalmente no caso dos alunos surdos adultos e que essas questões vão além da linguagem, carregam diferenças culturais que precisam ser consideradas durante o auxílio e mediação do professor.

Ao final da aplicação percebemos o envolvimento dos alunos participantes e a aceitação dos recursos tecnológicos apresentados, uma vez que todos relataram positivamente a necessidade e o apoio de tecnologias com metodologias voltadas a seu público.

No desenvolvimento do conhecimento precisamos acreditar na relevante importância que a tecnologia ocupa na educação. Percebemos que o acesso à tecnologia realmente muda a maneira como se vê e como se aprende o mundo e muda também a relação como o saber e com o outro. (LEVY, 1999, p.159). 


\section{CONSIDERAÇÕES FINAIS}

Salientamos que as dificuldades encontradas pelos surdos usuários da Libras no acesso à informação, à comunicação e à interatividade são as desafiadoras dessa pesquisa, bem como a intenção de rever metodologias utilizadas na EJA. Questionamos, também, o papel do conhecimento da cultura surda como principal ponto de desenvolvimento de habilidades cognitivas e sociais da pessoa com surdez.

A perspectiva inclusiva desafia os educadores a estabelecer uma proposta de ensino que reconheça e valorize práticas culturais dos alunos com deficiência. Isto sem perder de vista o conhecimento historicamente produzido, que constitui patrimônio de todos.

Ao pensarmos no compromisso e na ética do professor, nos reportamos ao espaço de discussão do projeto em questão: a escola na modalidade de educação básica para jovens e adultos. Nesse espaço, necessariamente, nos deparamos com diferentes características de escolarização se compararmos com o que consideramos as características da educação regular. É importante, neste contexto, analisar as diversas peculiaridades que estão envolvidas nessa forma de educação.

As habilidades que são adquiridas com a prática da navegação vão depender, não só do envolvimento pessoal e do conhecimento na utilização das tecnologias, mas também da possibilidade de acesso a todos, sem discriminação.

Portanto, a referida proposta de pesquisa leva em consideração uma construção de conhecimento fundamentada no pensamento pós-moderno que, na busca da análise das teorias existentes sobre o assunto, encontre subsídios no estudo da linguagem interativa e suas reflexões na aprendizagem do aluno jovem surdo. E, nas discussões sobre o processo inclusivo, pretende-se refletir e analisar, na teoria e na prática, as metodologias que utilizam os recursos tecnológicos, tratando-as como ferramentas auxiliares no desenvolvimento das atividades escolares dos alunos surdos de EJA.

O reconhecimento do direito à diferença e a consequente condenação de ideias e políticas que no passado o negaram tem-se traduzido em múltiplas intervenções do Estado: ações afirmativas de vários tipos, quotas para mulheres, afrodescendentes e indígenas, revisão profunda da história dos países e dos programas e conteúdos educativos, reconhecimento e proteção de línguas não-coloniais, direitos especiais à terra e ao território, por vezes, no âmbito do reconhecimento da autodeterminação interna. (SANTOS \& CHAUÍ, 2013, p. 80). 
É com base na análise aqui proposta que refletimos sobre as possíveis intervenções na busca de uma educação efetiva e de qualidade.

A humanização é a meta, e o conhecimento científico e filosófico são meios desse processo. Portanto, não deve ser separada a base intelectual, deve-se sim politizar e dar informação com a finalidade de tornar a pessoa sujeito do seu processo pedagógico.

\section{REFERÊNCIAS}

BRASIL. Lei no 9394/96, de 20 de dezembro de 1996. Estabelece as Diretrizes e Bases da Educação Nacional. Diário Oficial da União, seção 1. Brasília, 1996.

Lei 10.098, de 19 de dezembro de 2000. Estabelece normas gerais e critérios básicos para a promoção da acessibilidade das pessoas portadoras de deficiência ou com mobilidade reduzida, e dá outras providências. Brasília, DF. Disponível em: http://www.planalto.gov.br/ccivil_03/Leis/L10098.htm

CAMAS, N. P. V. Revista e-Curriculum: origens e evolução de um periódico científico eletrônico na área de educação e currículo construído na colaboração pedagógica. Tese de Doutorado em Educação: Currículo, PUC-SP, 2008.

CAMAS, N. P. V.; MANDAJI, M.; RIBEIRO, R. A.; MENGALLI, N. M. ( 2013). Professor e cultura digital: reflexão teórica acerca dos novos desafios na ação formadora para nosso. In: Revista Reflexão e Ação, Santa Cruz do Sul, v.21, n.2, p.179-198, jul./dez. 2013. Disponível em: http://online.unisc.br/seer/index.php/reflex.

COLL, César; MONOREO, Carles. Psicologia da educação virtual: aprender e ensinar com as tecnologias da informação e da comunicação. Porto Alegre; Artmed, 2010.

FERNANDES. Sueli de Fátima. Educação bilíngue para surdos: identidades, diferenças, contradições e mistérios. Tese de doutorado em Letras. UFPR, 2003.

QUADROS, Ronice Muller. Educação de surdos: a aquisição da linguagem. Porto Alegre: Artmed, 1997.

LEMOS, André; CUNHA, Paulo (orgs). Olhares sobre a Cibercultura .Sulina, Porto Alegre, 2003; pp. 11-23

LEVY, Pierre. Cibercultura. São Paulo : Ed.34, 1999.

LÜDKE, Menga; ANDRÉ, Marli E. D. A Pesquisa em educação: abordagens qualitativas. 2 ed. Rio de Janeiro: EPU, 2013.

PASCHUINI, ELENIRA APARECIDA. A infoinclusão de alunos surdos na educação de jovens e adultos utilizando o aplicativo Hand Talk em sala de aula. Dissertação (mestrado) - Universidade Federal do Paraná, Setor de Educação, Programa de PósGraduação em Educação. Defesa: Curitiba, 2015. 
PERLIN, Gládis Terezinha. Histórias de vida surda: identidades em questão. Dissertação de Mestrado em Educação - Universidade Federal do Rio Grande do Sul- UFRGS, Porto Alegre, 1998

SANTAELLA, L. Linguagens líquidas na era da mobilidade. São Paulo: Editora Paulus, 2007.

SANTOS, Boaventura de Sousa Santos e CHAUÍ, Marilena. Direitos humanos, democracia e desenvolvimento. São Paulo: Cortez, 2013.

SKLIAR, Carlos. Org. Atualidade da educação bilíngue para surdos. Vol. 2. Porto Alegre: Mediação, 1999.

SKLIAR, Carlos. Educação e exclusão: abordagens sócio-antropológicas em educação especial. 5.ed. Porto Alegre: Mediação, 2006.

STRAUSS, Anselm. Pesquisa qualitativa - técnicas e procedimentos para o desenvolvimento da teoria fundamentada: tradução Luciane de Oliveira da Rocha - 2.ed. Porto Alegre: Artmed, 2008.

STROBEL, K. L. A visão histórica da in(ex)clusão dos surdos nas escolas. Educação temática digital. Vol. 7, n. 2, p. 244-252, 2006. Disponível em http://www.brapci.ufpr.br/journal_edicao_artigos.php?dd0=15\&dd1=2006\&dd2=jun. $\% 20200$ $\underline{6 \& \mathrm{dd} 3=\mathrm{v} . \% 207 \& \mathrm{dd} 4=\mathrm{n} . \%}$

VYGOTSKY, L.S. A formação social da mente. 6 ed. São Paulo: Martins Fontes. 1998.

Pensamento e linguagem. São Paulo: Martins Fontes, 1988.

ZABALA, Antoni. A prática educativa: como ensinar. Porto Alegre: Editora Artes Médicas Sul Ltda, 1998. 